\title{
HEDONIC ANALYSIS OF FACTORS AFFECTING SALES PRICE OF FLATTED FACTORY UNITS: EVIDENCE FROM KOREA
}

\author{
Saejoon $\mathrm{OH}^{\star}$ \\ Department of Real Estate and Finance, Changshin University, 262 Palyongro MasanHoewon-gu, \\ Changwon, Gyeongnam 51352, Korea
}

Received 28 March 2018; accepted 14 December 2018

\begin{abstract}
Recently flatted factories have drawn attention as investment goods from developers and investors. The strengths and merits of these investments are that they are low priced and less strictly regulated. The purpose of this study is to empirically analyse the factors affecting the price of flatted factories by using the real transacted sales prices of 785 flatted factory units in Seoul and Gyeong-gi Province, Korea. A Hedonic Price Model (HPM) is employed for the study. The result finds that the price of flatted factories is affected by various factors: Location, Property, and Unit characteristics. In addition, the result outlines that flatted factories have commercial and industrial characteristics of both office buildings and factories. The result confirms that flatted factory price is affected by both industrial transportation accessibility and local transportation convenience. It also finds that property characteristics, such as gross area, age of the building, ratio of amenity facilities, core location, and parking space count are significant factors affecting the value. Moreover, the availability of floor level and two balcony unit types significantly relates to the price. Based on the results, it is also verified that the price of flatted factories is affected by factors similar to those of apartments or office buildings. This means that price decision factors of commercial and residential properties should be considered.
\end{abstract}

Keywords: flatted factory, industrial property, property value, sales price, hedonic price model.

\section{Introduction}

Recently in South Korea, many start-up businesses and small and medium sized companies have moved their company buildings into flatted factories due to the heavy burden of high rent in office buildings. As low interest rate policies have gained popularity in recent years, many investors began to take an interest in real estate as a way to generate stable income. Profitable real estate provides investors with a higher fixed income than other financial institutions. Since offices and commercial buildings have become oversupplied, their rate of return is not sufficiently guaranteed and investors have begun to draw their attention to other types of real estate such as industrial buildings (Cuadrado, Zubizarreta, Rojí, Larrauri, \& Álvarez, 2016). To support venture business and small and medium industry, the Korean government decided to enact favorable tax packages to firms using flatted factory buildings as their offices and financially support suppliers of flatted factories (Kim, 2016).

A flatted factory building, using the official name 'Knowledge Industry Center' in Korea, is a workplace in cities for both the manufacturing and knowledge-based industries. Unlike outlying provinces where manufacturing industry is the dominant form of business, flatted factories in Seoul and other metropolitan areas have been gaining popularity with the IT industry as substitutes for office buildings with high rent (Park, 2010). Even though there are strict terms and conditions for setting up a business in a flatted factory, the low sale price compared to an office building is the big attraction for small and medium industry and venture businesses (Korea Industrial Complex Corporation [KICOX], 2013). Firms in flatted factories receive benefits in the form of tax reductions: 50\% reduced acquisition tax and $37.5 \%$ reduced property tax, achieving 5 6\% fixed rental income per year (Park \& Lee, 2015; Korea Land \& Housing Corporation [KLHC], 2011). Since firms in flatted factories are mostly corporate bodies, long-term contracts are often secured. Many construction firms have recently joined this business as a response to its increasing demand. Recently, the investment scale of flatted factories has grown even larger and accordingly factory rent prices are declining (KLHC, 2011). In general,

${ }^{*}$ Corresponding author. E-mail: saoh2@naver.com 
many flatted factories, a new profitable real estate sector, have gained popularity for office use, rather than industrial purposes (Jung \& Choi, 2013). They replace the demand for office buildings.

Even though supply of flatted factories has increased, related academic research has yet to follow. Studies on flatted factories are needed and necessary regarding location, selection factors, actual demand and investment, price determinants, and so on. In this study, factors which affect the price of flatted factories are empirically analyzed. In addition, this study uses the real transaction prices from the market, enhancing reliability. It also presents both guidelines and implications not only to firms with actual demand, but to investors for more informed decision making, and further to policy makers for the industrial property policy making process.

The study process is as follows. First, it examines the historical background of flatted factories. Second, it reviews the goal of the flatted factory policy and market conditions. Third, by reviewing earlier studies, it tries to thoroughly examine which types of variables and characteristics actually affect the sale price of flatted factories by using a hedonic price model (HPM). The actual market transaction data which has been collected and implemented: 785 separate units of 21 flatted factories in Seoul metropolitan area.

\section{Historical backgrounds}

\subsection{Characteristics of a flatted factory}

The concept of a flatted factory first started in Rotterdam, Netherlands in 1942, and became widely used as a way to prevent deindustrialization in big cities across Europe. Flatted factories have quickly spread among countries suffering from a short supply of industrial land, such as Taiwan, Hong Kong, and Singapore.

Hong Kong is internationally renowned as a leader in the trend of implementing flatted factories in order to effectively overcome limited land space. Since 1960, Hong Kong has built 10-story or greater developments led by private companies, and sold in parcels or leased to small and medium sized companies. As for Singapore, the government established a non-profit organization, 'Juryong City Corporation', in 1963, and started to build low-cost 'standard', and 'apartment type' factories.

A flatted factory, also known as 'knowledge industry center' in Korea, is defined as a multi-story, multi-owned building where manufacturing knowledge and info-communication industries are all located together in one or two buildings (Industrial Cluster Development and Factory Establishment Act [ICDFEA], Article 2, $6^{\text {th }}$ ). On the other hand, a business park is a multi-building complex that not only accommodates a mix of activities such as storage, light manufacturing, research, and office functions integrated in park-like setting with supporting uses (ULI, 2001).

In the middle of the 1990s, the 'Special Act for the Development of Venture Business' was introduced, and firms and supplying constructors of flatted factories received benefits in the form of tax favors and construction cost support (Park, 2009). Recently, super-sized premium flatted factories are PF funded and well-equipped with state-of-the-art facilities, making them suitable substitutes for office buildings. The demand for flatted factories varies: from actuality to investment.

A flatted factory is a clean and efficient work place equipped with various facilities. Flatted factories are usually located in metropolitan areas with convenient accessibility, an easy supply of labor, and cost-reducing logistics. Since similar types of industry are grouped together in flatted factories, their cooperation is expected to generate a synergetic effect. Flatted factories have broken the image of the traditional, outdated factory and grown to become state-of-the-art premium buildings (see Figure 1 and Figure 2).

Flatted factories located in industrial complexes are not allowed to do lease business with registration until factory registration is completed. However, flatted factories located outside of industrial complexes are allowed to do lease business to all clients. In this regard, flatted factories outside industrial complexes are attracting investors looking for properties for rent profit (Oh, 2016).

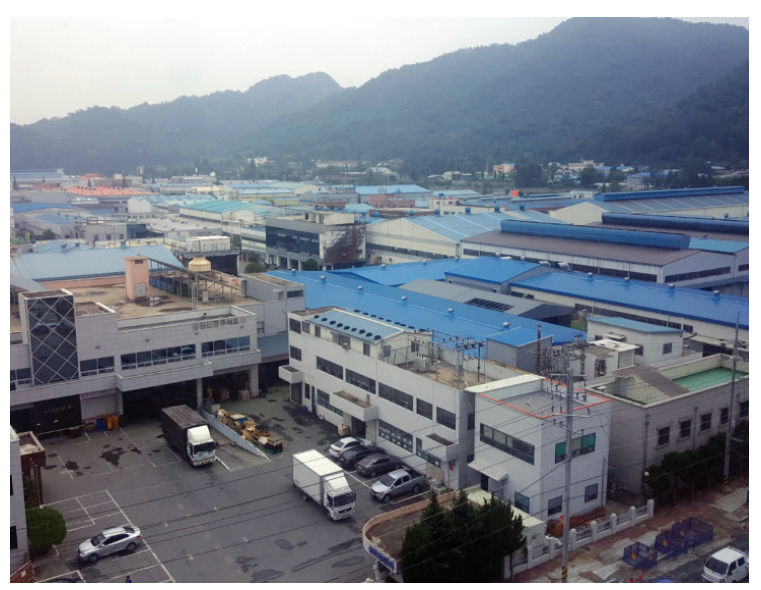

Figure 1. Example of a flatted factory (left) vs. regular factory (right) in Korea (source: author) 


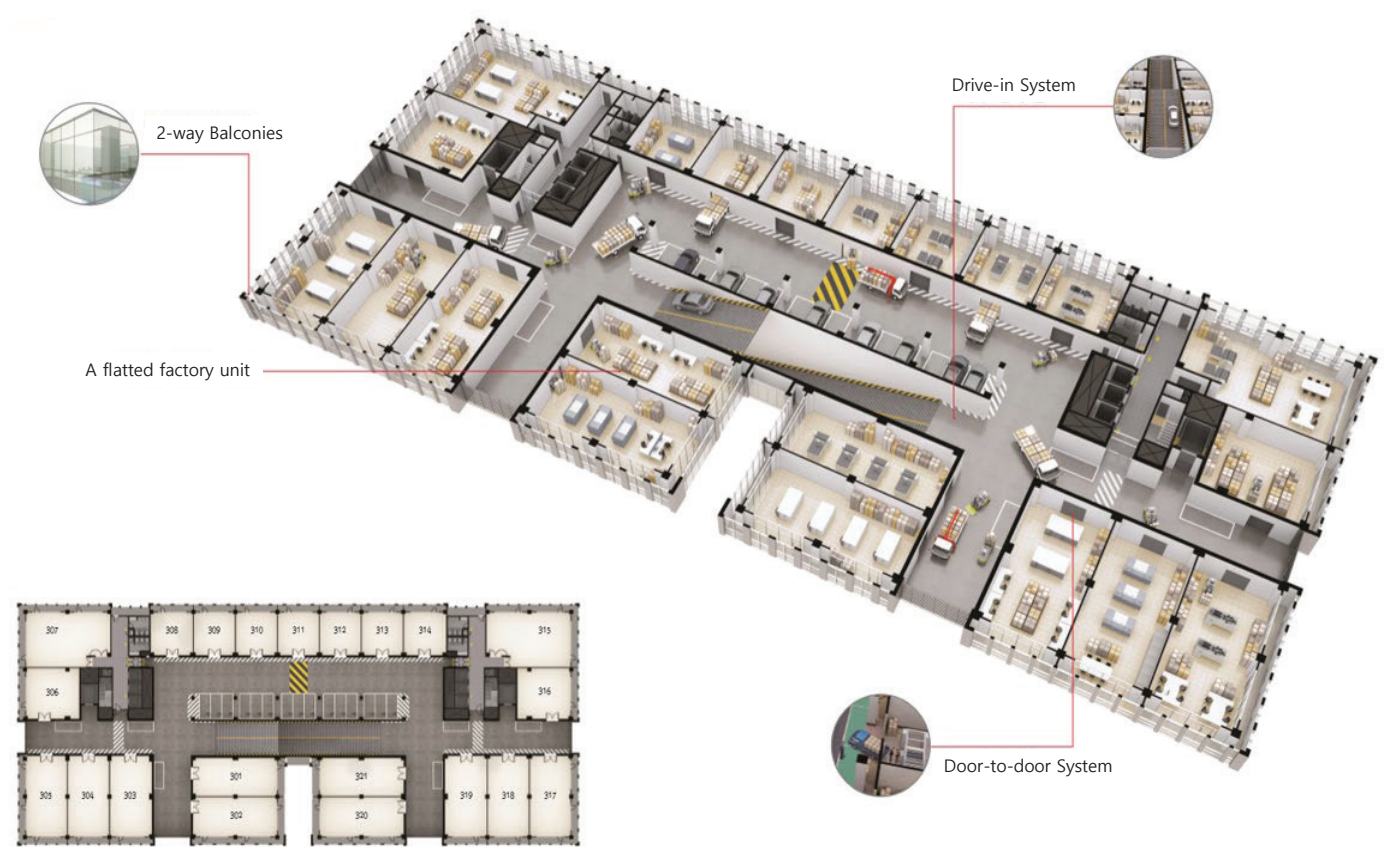

Figure 2. Example of a flatted factory inside (source: SK V1 Center, available from http://www.skv1center.co.kr/)

Flatted factories however, do have weaknesses. Though flatted factories are relatively inexpensive compared to office buildings, offices in flatted factories can face high levels of noise due to existing industrial facilities in the same building; there may also be lack of amenities or parking spaces. There are rarely overlapping business among firms in flatted factories, so that cooperation and networking opportunities are difficult to realize. The strengths and weaknesses of flatted factories are displayed in Table 1.

Recent flatted factories are mostly used for offices of emerging industries rather than for existing manufacturing firms. The supply of flatted factories has continuously increased after being excluded from the Total Industrial Site Volume Control System (TISVCS) applied in the Seoul metropolitan area. The Ministry of Land, Infrastructure, and Transport (n.d.) officially announced the Total Industrial Site Volume Control System (TISVCS) to regulate the total volume of industrial infrastructure in the Seoul metropolitan area. However, flatted factories are excluded, provided that they do not cause any type of environmental issues.
Therefore, it is not easy for small and medium sized manufacturing companies to build their factories in the expensive Seoul metropolitan area with higher regulations. Flatted factories can offer an alternative for small and medium sized manufacturing companies as an optimal place for efficient work places. As a result, the number of flatted factories has drastically increased in metropolitan areas in South Korea (Kim, 2009).

As the economic growth rate slows, the Korean government has decided to enact favorable tax packages to firms using flatted factory buildings as their offices and financially support suppliers of flatted factories to promote and support venture business and small and medium industry. According to Article 58 in the Local Tax Exemption Act, firms in flatted factories receive the following tax reduction benefits: 50\% reduced acquisition tax and 37.5\% reduced property tax. However, acquisition taxes are imposed if flatted factories are not used for more than a year after the date of acquisition, or sold off within 5 years after their acquisition. In addition, facility aid funding (long-term low interest loan) is available for up to $70 \%$ of the factory value. These types of benefits are not applied to office buildings.

Table 1. Strengths and weaknesses of a flatted factory (source: Industrial Land Information System: http://www.industryland.or.kr)

\begin{tabular}{|l|l|}
\hline \multicolumn{1}{|c|}{ Strengths } & \multicolumn{1}{c|}{ Weaknesses } \\
\hline - Synergy effect increases due to similar industry community & - Backwardness of facilities \\
- Cost reduction due to common use of facilities & - Design focused on manufacturing industry \\
- Productivity enhancement due to efficient work space & - Limited parking space and inconvenience of parking \\
- Logistics cost reduction and easy labor force supply due to & system \\
closeness to CBD (Central Business District) & - Lack of subsidiary facilities, and oversupplied \\
- Outside credibility improvement of firms in flatted factories & neighborhood living facilities \\
- Government support for tenants of flatted factories & - Power shortages (electricity) \\
\hline
\end{tabular}


Therefore, this is one of the reasons why small and medium companies are hesitant to become office building tenants and are transferring to flatted factories instead.

\subsection{Goal of flatted factory policy}

A flatted factory is representative of an industrial property which maximizes land use in a metropolitan area where industrial lots are scarce. Flatted factories offer modernized, convenient facilities for enhanced productivity and supportive clustering of dispersed small and medium sized factories to improve the urban landscape (Lee, 2011).

As shown in Table 2, the goals of flatted factory policy are as follows: Firstly, long-term and large-scale industry in the metropolitan areas has been replaced by high-technology industry to meet the demand for lower rent for workplaces. Secondly, the increase of small industry without development planning in big cities causes the deterioration of the town. To prevent development without planning and to maximize land use in the metropolitan area, small industry needs to be clustered together in flatted factories. Thirdly, small-sized, high-technology industry may cluster together to build the foundation for cost-ef- fective operation equipped with networked infrastructure, eventually to improve its competitive power in the global market (Chang \& Lee, 2009; J. W. Lee \& C. M. Lee, 2006).

\subsection{Current supply status of flatted factory}

The number of flatted factories nationwide totaled 792 in 2016; 290 in Seoul, approximately 37\%, and 279 in Gyeonggi Province, approximately $35 \%$. About $72 \%$ of flatted factory buildings are clustered in Seoul and Gyeong-gi area.

This high concentration is due to companies' preference for flatted factories located in Seoul and Gyeonggi area, since their supreme location provides sufficient manpower, available markets, and necessary information and technology. Consequently, flatted factories are mostly supplied around Seoul and Gyeong-gi area.

As shown in Table 3, the distribution of the number of companies in flatted factories are as follows: 11,393 (44.0\%) companies out of total 25,890 in Seoul, 9,295 (35.9\%) in Gyeong-gi province, 2,038 (7.9\%) in Busan, and 1,247 (4.8\%) in Incheon. About $80 \%$ of companies in flatted factories are clustered in the greater Seoul metropolitan area.

Table 2. Flatted factory policy goal and expected effects (source: Lee, 2011)

\begin{tabular}{|l|l|l|}
\hline \multicolumn{1}{|c|}{ Policy goal } & \multicolumn{1}{|c|}{ Issues } & \multicolumn{1}{c|}{ Expected effect } \\
\hline Solving land shortages & Industrial land shortage in CBD & $\begin{array}{l}\text { Integration and enhancement (higher } \\
\text { density) of land use }\end{array}$ \\
\hline Enhancing the city environment & $\begin{array}{l}\text { Deterioration of residential areas and } \\
\text { functional role of a city due to invasive } \\
\text { small and medium factories }\end{array}$ & $\begin{array}{l}\text { Clustering of factories and improvement } \\
\text { of urban landscape }\end{array}$ \\
\hline Securing self-owned factories & $\begin{array}{l}\text { Unstable working condition of firms due } \\
\text { to factory rent/lease }\end{array}$ & $\begin{array}{l}\text { Securing a self-owned factory at an } \\
\text { affordable price }\end{array}$ \\
\hline Invigorating the local economy & $\begin{array}{l}\text { Low-income urban dwellers' loss of } \\
\text { income due to absence of manufacturing } \\
\text { industry firms in a city }\end{array}$ & $\begin{array}{l}\text { Factories closely located to homes which } \\
\text { do not hinder the residential environment } \\
\text { Convenient supply of manpower to } \\
\text { factories in a large city }\end{array}$ \\
\hline $\begin{array}{l}\text { Enhancing competitiveness of small and } \\
\text { medium industry }\end{array}$ & $\begin{array}{l}\text { Burden of maintaining supporting } \\
\text { facilities in small firms }\end{array}$ & $\begin{array}{l}\text { Common use of supporting facilities } \\
\text { Maintenance cost reduction on account } \\
\text { of facility management in large scale } \\
\text { (economy of scale) }\end{array}$ \\
\hline $\begin{array}{l}\text { Exchanging information and cooperation } \\
\text { among firms }\end{array}$ & $\begin{array}{l}\text { Necessity of information and technology } \\
\text { exchange among related firms }\end{array}$ & $\begin{array}{l}\text { Interaction with similar and dissimilar } \\
\text { industry due to factory clustering }\end{array}$ \\
\hline $\begin{array}{l}\text { Improving working environments } \\
\text { Deteriorated working conditions due } \\
\text { fo underground work spaces of small } \\
\text { factories in a large city }\end{array}$ & $\begin{array}{l}\text { Improvement of productivity and working } \\
\text { environment due to modernized facilities }\end{array}$ \\
\hline
\end{tabular}

Table 3. Number of flatted factories (Nationwide) (source: Kim, 2016)

\begin{tabular}{|l|c|c|c|c|c|c|c|c|c|}
\hline & Seoul & Gyeong-gi & Incheon & Busan & Gyeong-nam & Daejeon & Daegu & Etc. & Total \\
\hline Building & 290 & 279 & 50 & 43 & 28 & 12 & 24 & 66 & 792 \\
& $(36.6)$ & $(35.2)$ & $(6.3)$ & $(5.4)$ & $(3.5)$ & $(1.5)$ & $(3.0)$ & $(8.5)$ & $(100)$ \\
\hline Companies & 11,393 & 9,295 & 1,247 & 2,038 & 880 & 98 & 440 & 499 & 25,890 \\
& $(44.0)$ & $(35.9)$ & $(4.8)$ & $(7.9)$ & $(3.4)$ & $(0.4)$ & $(1.7)$ & $(1.9)$ & $(100)$ \\
\hline Site area & 1,690 & 2,505 & 399 & 323 & 496 & 115 & 196 & 763 & 6,487 \\
& $(26.1)$ & $(38.6)$ & $(6.2)$ & $(5.0)$ & $(7.6)$ & $(1.8)$ & $(3.0)$ & $(11.7)$ & $(100)$ \\
\hline Gross area & 15,901 & 10,236 & 2,375 & 870 & 822 & 336 & 307 & 1,444 & 32,291 \\
& $(49.2)$ & $(31.7)$ & $(7.4)$ & $(2.7)$ & $(2.5)$ & $(1.0)$ & $(0.9)$ & $(4.6)$ & $(100)$ \\
\hline
\end{tabular}




\section{Literature review}

Recently, flatted factories are mainly being built and developed in leading countries in Asia, such as Singapore (a.k.a. flatted factory building), Taiwan (a.k.a. standard factory building), and Hong Kong (a.k.a. factory building). Their common features are high land value and strategic support in the manufacturing industry in metropolitan locations (Kim, 2009; Park, 2009; Lee, 2011; Lee \& Kim, 2014). However, there have not been many studies on this subject; and it is difficult to find research regarding flatted factories' value. The extent of earlier literatures are not just limited to flatted factories value, and is rather extended to industrial properties' price decision as well.

There are two price estimation methods: the traditional and statistical method. Market, cost, and income approaches are considered in the traditional method; theoretical feasibility is established based on Alfred Marshall's established theories and research, though not much empirical analysis has been done. On the other hand, statistical price estimation methods have been vigorously studied. Research using multiple regression models including Hedonic Price Models are widely available.

Ambrose (1990) compared the asking price and asking rent of industrial properties in Atlanta, USA, and analyzed factors affecting the price of industrial properties. The result showed that the asking price of warehouses was affected by factors, such as building square feet, availability of office space, number of truck accessible dock doors, presence of railroad siding, and Build-To-Suit (BTS) office space. Asking rent was affected by office space, ceiling height, number of truck accessible dock doors, number of drive-in doors, and presence of sprinkler system. However, location factors were not considered in the study.

Kowalski and Paraskevopoulos (1990) reexamined the relationship between location and the value of industrial land based on sales data of 56 industrial properties in suburban communities of Detroit, USA. The result showed expressway visibility, plot location within the industrial park, and number of frontage feet available to the parcel positively affected the price. On the other hand, size of parcel in acres negatively affected price. Besides distance to CBD, other factors were found to be significant. Especially, the study insisted that industrial land equipped with expressway visibility showed 56\% higher land price level as compared to the opposite.

Fehribach, Rutherford, and Eakin (1993) studied price decision factors by utilizing data from 170 industrial building transactions in the Dallas/Fort Worth area, USA. The study added location and economic variables which were not included in Ambrose's (1990) study. The area of industrial buildings was examined as rentable area. The factors affecting price were as follows: building size, office space, number of truck accessible dock doors, ceiling height, age, distance from the Dallas/Fort Worth Airport, type of tenant, cap rate, and prime rate.

Lockwood and Rutherford (1996) analyzed the pricing factors of industrial properties by using a LISREL model.
The result showed that physical characteristics (land size, work area), regional market conditions (local employment rate, local income, GRDP), and location characteristics (distance to CBD, airport, major roads, railways) affected the price of industrial properties.

Dunse, Jones, Brown, and Fraser (2005) analyzed the relationship between rent depreciation and building location and deterioration of industrial properties in Glasgow, Scotland. Rent prices decreased as buildings and interior facilities deteriorated, located further from motorway junctions or the CBD.

Hwang and Choi (2014) examined customer satisfaction levels and the intention of recommendation for offices in Seoul Digital Media Business District. According to their research, significant factors were institutional factors (tax favors, kindness and support of the Industrial Complex Corporation, availability of consultation for loan and support), location and environmental factors (location, accessibility, ease of public transportation access), and business factors (accessibility to targeted market, school-work links, manpower planning). However, the result showed that economic factors (low sale price, maintenance expenses, neighborhood living cost) were insignificant, so they were rejected. The authors explained it was because offices in Seoul Digital Media Business District were located near newly developed, relatively inexpensive city districts.

Beekmans, Pascal, Erwin, and Karel (2014) analyzed price decision factors for industrial sites in the Netherlands between 1997 and 2008. The study was based on the industrial site price for tax purposes as the dependent variable over time. The result showed significant factors that favored locations near motorways, sea ports, in densely populated areas, with public transportation access, housing within a $500 \mathrm{~m}$ radius, and available water supply. However, as Derbes (2002) argued that the appraisal price was not suitable for analyzing industrial properties' true value. This was not the actual transaction price nor did it account for equipment facilities when sold.

The above discusses studies related to the price of industrial properties. Strictly speaking, they do not analyze specific flatted factories data. Under the circumstances, this study aims to be the first to methodically analyze factors affecting the value of flatted factories by using real transaction price data from the market. This study can be differentiated from earlier studies, in that, it analyzes new variables through flatted factories: accessibility to metropolitan transportation, traffic convenience in a city, ratio of amenity space, presence of two-way balconies, and so on.

\section{Study area and data}

Approximately eighty percent of flatted factories in Korea are located in Seoul and Gyeong-gi Province, and are provided relatively inexpensively to small and medium sized companies and start-up businesses. In this study, the data was collected by obtaining the transaction prices of 785 units in 21 flatted factories in Seoul and Gyeong-gi Province, see Figure 3. The sales data from the market is 


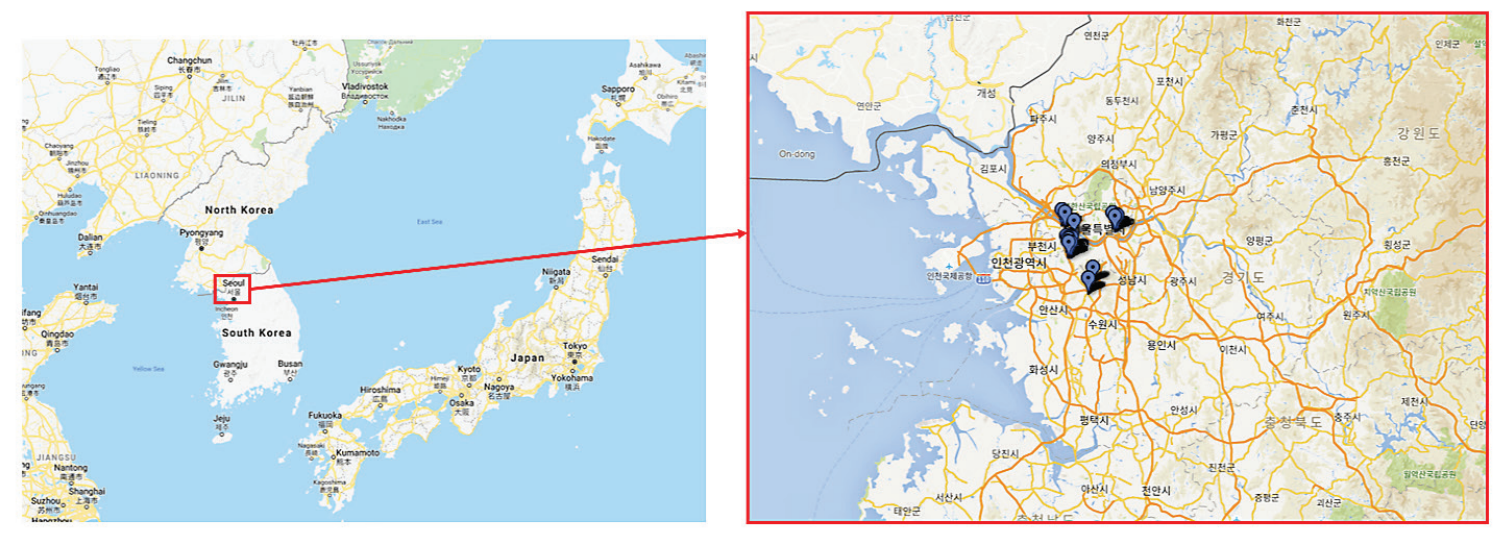

Figure 3. Study area (source: Google Map Service and Google Fusion Table, n.d.)

collected from the Appraisal Information System (a.k.a. R-One system) from the Ministry of Land, Infrastructure and Transport, operated by the Korea Appraisal Board, for the time period from the year of 2014 to 2016.

To prevent distortion of the model, this study excluded the sales price of amenity units in flatted factories from the data sample. There exists a price discrepancy between amenity and factory facilities due to their different characteristics.

Data for the location characteristics factor, i.e. distance to the metro station, is collected from google maps; data for building and unit characteristics are collected from sales agencies, construction firms, and the Government Civil Petition Service (n.d.) portal.

\section{Methodology}

A hedonic pricing model (HPM) is used to empirically analyze factors affecting the sales price of flatted factory units. The concept of Hedonic Price Model was first applied by G. C. Hass in 1922, substantially earlier than A. T. Court in 1939 (Coldwell \& Dilmore, 1999), and Lancaster (1966) and Rosen (1974) established its theoretical framework. The Hedonic Price Model is based on the assumption that various characteristics of independent variables affect one dependent variable.

HPM is mostly used for price and value estimation (Buttimer, Ronald, \& Ron, 1997). Rosen (1974) built the theoretical background of the Hedonic Price Model. HPM is the major indirect implementation method for evaluating value of benefit by using market data; goods are made up of various features and each attribute has its own use. These factors are analyzed by using a multiple regression analysis, and that is the hedonic price model. The value of goods is determined by the sum of its use (Lancaster, 1966). This model is based on a statistical analysis that characterizes the price of flatted factory unit as a dependent variable, and factors such as location, property, and environment characteristics are employed as independent variables in order to explain the dependent variable (Keskin, 2008).
In Hedonic Price Models, one model is selected: Liner, Semi-Log, or a Double-Log Model. There is no theory for selecting one above of the other two. As for a linear function, the explanation for estimated results is simple. However, when the quantity or number of characteristics becomes too large, it is difficult to interpret the results as they reach a near identical rate with larger or numerous variables. DiPasquale and Wheaton (1996) argued that a Double-Log Model seemed plausible in this respect. This model could reflect the law of diminishing marginal utility of real estate price and characteristics by using double logarithmic function. However, double-log models have difficulty in processing and interpreting dummy variables. A dummy variable has value of 0 or 1 , but $\log 0$ is not defined so that it cannot take natural logarithms. Therefore, a linear function is selected in this study.

To set an appropriate model, missed variables should be carefully considered. Variable omission has the possibility to occur, since all the major characteristics affecting real estate price are not included as independent variables. In addition, we do not recognize all the characteristics in the real estate market which affect real estate price, and even if we do, it is difficult to observe and determine their exact value. For this reason, when the significant characteristics are missing in the model, the estimated result possibly shows bias. Therefore, the selection of variables should be done with extreme caution. To supplement this bias, this study has tried to expand on literature of industrial properties to select the optimal variables for the purpose of the study.

To build the model for analyzing factors affecting the purchase and sale price of flatted factories, the real transaction price per unit is set as the dependent variable $(P)$ instead of a nominal price to control for the possible effect of time (Mesthrige \& Poon, 2015); The model takes the following formula (Eq. (1)):

$$
P=\alpha+\sum_{i=1}^{i=n} \beta_{1} L O_{i t}+\sum_{i=1}^{i=n} \gamma_{2} P R_{b t}+\sum_{i=1}^{i=n} \delta_{3} U N_{p t}+\epsilon
$$

where: $P$ denotes the price per unit size $\left(\mathrm{m}^{2}\right)$ of property; $\alpha$ is a constant; $\epsilon$ is a vector of random error term; 
Table 4. Consumer Price Index by the year $(2010=100)$ (source: Korean Statistical Information Service, n.d.)

\begin{tabular}{|c|c|c|c|c|c|c|c|c|c|c|c|}
\hline $20141 \mathrm{Q}$ & $2 \mathrm{Q}$ & $3 \mathrm{Q}$ & $4 \mathrm{Q}$ & $20151 \mathrm{Q}$ & $2 \mathrm{Q}$ & $3 \mathrm{Q}$ & $4 \mathrm{Q}$ & $20161 \mathrm{Q}$ & $2 \mathrm{Q}$ & $3 \mathrm{Q}$ & $4 \mathrm{Q}$ \\
\hline 108.76 & 109.13 & 109.36 & 108.90 & 109.37 & 109.71 & 110.10 & 110.06 & 110.49 & 110.65 & 110.95 & 111.31 \\
\hline
\end{tabular}

LO denotes location characteristics of site $(i)$ in year $(t)$; $P R$ denotes property characteristics of building $(b)$ in year $(t)$; UN denotes unit characteristics of property $(p)$ in year $(t) ; \beta_{1}, \gamma_{2}$, and $\delta_{3}$ are estimated coefficients.

In this data, transactions have been carried out between 2014 and 2016. However, the price of flatted factories does not increase annually as residential properties do. It is because only business operators may buy flatted factories, and the category of business is also limited. Even though profits on sales are not high enough, the reason why flatted factories are favored is rental profit, tax favor, and loan support. In this situation, if a time dummy variable is applied, it may show insignificant results. Therefore, in this study, as Lockwood and Rutherford (1996) applied, a Consumer Price Index (CPI) is used to adjust the price level during that time period. Average CPI by the year is as follows (Table 4).

\section{Variables and hypothesis}

The dependent variable of the model is set as the real transaction price per unit size in a flatted factory unit.

Independent variables are set as location characteristics, property characteristics, unit characteristics, and regional economic characteristics. Variables are displayed in Table 5.

\subsection{Location characteristics}

First, to control the discrepancy between a flatted factory in an industrial district and a detached flatted factory in the case of area characteristics, a control variable is set when a flatted factory is located in the National Industrial Complex. A national industrial complex is an area zoned and planned for the purpose of industrial development. A flatted factory could be located either inside or outside of National Industrial Complexes. National Industrial Complexes are industrial complexes designated by the government to develop technology-intensive industry, infrastructure, and state-of-the-art technology. An industrial complex is intentionally and strategically made by the government, so that it offers low land price and stable infrastructure. Therefore, if a flatted factory is located in a national industrial complex, the sales price would be lower than outside of an industrial complex.

Second, to control the price gap between regions, a regional dummy variable is applied (Gyeong-gi Province vs. Seoul). Property price located in Seoul is higher than in the peripheral area (i.e. Gyeong-gi Province) due to land price and other factors.

Third, since the logistics of industrial properties, such as industrial transportation accessibility and related factors, are critically important for these properties, distance to expressway interchanges from factory buildings is measured. Moreover, flatted factories are used as both industrial properties and office buildings, so that employees' transportation easiness factor should be considered; traffic in a city, such as nearest major arterial roads, or public transportation are taken into account.

It is expected that office prices go up, when they face a main street or are located near metro stations or bus stops (Yui \& Wong, 2005). However, flatted factories are just factories. Head offices simply coexist with manufacturing firms in a flatted factory, so companies should consider metropolitan transportation networks, such as expressways and major arterial roads. To measure the influence of public transportation accessibility, the straight distance between subway stations and flatted factory buildings is applied.

If a factory is located along a main street, it has easy access to reach major arterial roads and visibility. If a flatted factory has a wide front road, it is expected to have a positive impact on the price since it relates to ease of access to the parcel and its possibility of development (Kowalski \& Praskevopoulos, 1990).

$\mathrm{H} 1$ : In addition to industrial transportation convenience, traffic convenience within a city will have a positive effect on value.

Flatted factory buildings are frequently used for startup businesses and head offices for research centers. Recently, they tend to be located near Central Business Districts (henceforward, CBD) on account of their competitive price. They are in high demand since consumers pay less expensive rent compared to office buildings. Therefore, factors affecting the price of office buildings might have relevance to those of flatted factories. For the distance to CBD variable, Kryvobokov and Wilhelmsson (2007) applied the central point of a cities' central square, considered center of Donetsk as the CBD. In this paper, the straight distance between center of Seoul and the building is measured.

\subsection{Property characteristics}

The property characteristics and quality of a building are expected factors affecting the value of a flatted factory. In this business, as a matter of building scale, a flatted factory building with a gross area of over $60,000 \mathrm{~m}^{2}$ is considered to be a grade 'A'. Ample spaces provide a variety of convenient facilities and enhance working environments. As for high-rise buildings, in addition, they tend to collect higher rent profits compared to lower height buildings. Consequently, high-rise flatted factories with views have relatively higher prices for rent and sales than those without views. A flatted factory has similar characteristics to an office building; the sales value of a unit is almost similar to that of an office building. If the size of a flatted factory got bigger, they attracted more factories and facilities, which 
generated a synergy effect and eventually caused the sale and rent price to increase. Therefore, it is expected that the value of a unit in a flatted factory is higher when the gross area (total flatted factory size) is bigger.

H2: Large scale flatted factories will have a positive relationship with their value.

Second, the building age, showing the deterioration of a building, is calculated by the period from the authorized completion year to the year of the investigation. If a building is getting older, facilities become dilapidated or outmoded and its rent will decrease. As most of previous studies used this variable, building age is expected to have negative relationship with the value of a building.

Third, amenity facilities are restricted to use only to support tenant firms or those which expand employees' welfare: finance, insurance, education, medical treatment, trade, sales facilities (products should be directly manufactured by the residing firms only), logistics facilities, daycare centers, and dormitories for factory employees. The ratio of amenities should be less than $30 \%$ of a flatted factory building (KICOX, n.d.). The higher the ratio of amenities, the more convenience to occupying firms in flatted factories. This benefit positively influences value of flatted factories.

H3: The higher the ratio of amenity facilities, the higher the value of the building because of the wider variety of convenient facilities available.

Fourth, about core structure type, center-core building layouts are preferred to either one-sided core or dispersedcore types. Dispersed-core type layouts are not favored among residents since stairs, elevators, or restrooms are located only in one side of the structure. It is expected that center-cored building variables will have positive correlation with their price.

Last, to have more parking spaces than legally required is the great feature for the sales marketing of a flatted fac- tory. Since both the number of available parking spaces and gross area (total building floor area) have multi-collinearity, the number of available parking spaces per gross area of the building is measured.

\subsection{Unit characteristics}

First, with respect to characteristics of each unit, if a unit is located on the higher floor level, the value would be higher because of the better exterior view. The distance between an elevator and a unit is measured by a straight line between the two. A closer distance to an elevator from a unit is expected to produce a higher value.

A corner unit that has two balconies is regarded as a dummy. Balconies provide view, ventilation, and natural lighting. If a unit is located on a corner, this unit could guarantee two balconies (see Figure 4).

H4: If a unit has two way balconies, it is expect to positively impact the value.

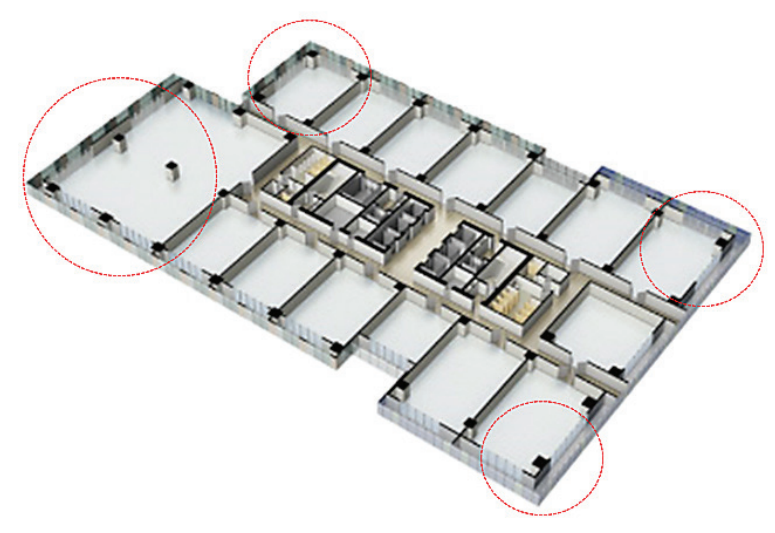

Figure 4. Example of a two way balconies unit (source: Lotte Higgs U Tower, available from http://www.lottehiggs.com/index.php)

Table 5. Variables description

\begin{tabular}{|c|c|c|c|c|}
\hline Categories & Variables & Definition & Unit & Exp. Sign \\
\hline $\begin{array}{l}\text { Dependent } \\
\text { variable }\end{array}$ & Sales price per unit & (Sale price / unit size) / (CPI / 100) & $\mathrm{USD} / \mathrm{m}^{2}$ & \\
\hline \multirow{7}{*}{$\begin{array}{l}\text { Location } \\
\text { characteristics }\end{array}$} & National industrial complex & If the building is located in Nat'l industrial complex $=1$ & Dummy & - \\
\hline & Gyeong-gi province & If the building is located in Gyeong-gi province $=1$ & Dummy & - \\
\hline & Distance to expressway & Distance between the building and expressway interchange & $\mathrm{km}$ & - \\
\hline & $\begin{array}{l}\text { Distance to major arterial } \\
\text { roads }\end{array}$ & Distance between the building and major arterial roads & $\mathrm{km}$ & - \\
\hline & Distance to subway station & Distance between the building and subway station & $\mathrm{m}$ & - \\
\hline & Width of front road & Width of front road of the building & $\mathrm{m}$ & + \\
\hline & Distance to CBD & Distance between the building and center of Seoul & $\mathrm{km}$ & - \\
\hline \multirow{5}{*}{$\begin{array}{l}\text { Property } \\
\text { characteristics }\end{array}$} & Gross area & Total floor area of the building & $\mathrm{m}^{2}$ & + \\
\hline & Age & Age of the building & year & - \\
\hline & Ratio of amenity & Ratio of amenities in the building & $\%$ & + \\
\hline & Center cored & If center cored building (vs. eccentric core) $=1$ & Dummy & + \\
\hline & Parking lot per gross area & Parking space per gross area of the building & $\mathrm{m}^{2}$ & + \\
\hline \multirow{3}{*}{$\begin{array}{l}\text { Unit } \\
\text { characteristics }\end{array}$} & Unit floor & Floor level of the unit & Floor & + \\
\hline & Distance to elevator & Distance between the unit and elevator & $\mathrm{m}$ & - \\
\hline & Two way balconies & If the unit has two balconies $=1$ & Dummy & + \\
\hline
\end{tabular}




\section{Descriptive statistics}

Descriptive statistics of the selected data sample in this study are as follows: Sales prices were 104,667 1,375,889 USD, approximately 451,516 USD on average. The distance to expressway interchanges is about $3.1 \mathrm{~km}$ on average: the average distance to major arterial roads, $1.25 \mathrm{~km}$ : the distance to subway station, $0.55 \mathrm{~km}$ on average. The width of roads bordering the front of buildings ranges from a minimum of $10 \mathrm{~m}$ to the maximum of $44 \mathrm{~m}, 21.06 \mathrm{~m}$ on average. The size of gross area is from $24,312 \mathrm{~m}^{2}$ to $212,733 \mathrm{~m}^{2}$, with an average of $108,764 \mathrm{~m}^{2}$. The age of the buildings ranges from 2 to 11 years, 5.03 years on average, and most of buildings were built after the year 2000. The total number of floors from the ground floor to the top level ranges from 11 to 40 floors, 23 floors on average. The ratio of amenity facilities is from $8 \%$ to $29.97 \%, 16.5 \%$ on average. Descriptive statistics are shown in Table 6.

\section{Results and findings}

In this study, to verify the effect of industrial transportation accessibility and local traffic convenience in a flatted factory, the distance to expressway interchanges, arterial roads, and subway stations are selected as variables. However, they are divided into model 1 and model 2 due to multi-collinearity. Model 2 of Table 7 differs from model 1 only in terms of distance to major arterial roads (vs. distance to expressway IC). Multi-collinearity may create misleading results and lead to erroneous interpretation of regression results. The calculated VIFs for variables in Table 7, show no evidence of multi-collinearity in the models.
Homoscedasticity where the scatter plot of standardized residuals against predicted values should be checked whether the variance of the residual terms is evenly dispersed. Also, the normal Probability-Probability (P-P) plot of regression standardized residuals can be used to assess whether the residuals are normally distributed variables with a mean of zero (Zhang, Li, Stephenson, \& Ashuri, 2018).

In Figures 5 and 6, different types of residual plots are applied: including a normal probability plot and a scatter plot. To assess the quality of the regression analysis, residual plot pattern analysis was conducted. The normal P-P plot of residuals shows an approximately linear pattern, which means the error terms are normally distributed and meets the normality assumption. The standardized residuals of the scatter plot against predicted values are calculated from the developed regression model, showing a random pattern on both zero standard residual lines. The assumptions of homoscedasticity and independence of the data using to develop the Hedonic Price Model are both seem to be satisfied.

The results of the regression model explain each characteristic in the following: First, in respect of location characteristics, it is confirmed that all variables negatively affect factory value. The sales price of flatted factories located in National Industrial Complexes show significance in a negative way. There exists a price difference for sale between flatted factories within the National Industrial Complexes and detached flatted factories. Land price in the National Industrial Complexes is relatively inexpensive compared to detached / isolated flatted factories. It seems that there are regulations that firms in the National Industrial Complexes should follow, such as a factory registration process or occupancy agreement.

Table 6. Descriptive statistics $(\mathrm{N}=785)$

\begin{tabular}{|c|c|c|c|c|c|}
\hline Variable & Unit & Minimum & Maximum & Mean & S.D. \\
\hline National industrial complex & dummy & 0.0 & 1.0 & 0.19 & 0.40 \\
\hline Gyeong-gi province & dummy & 0.0 & 1.0 & 0.22 & 0.41 \\
\hline Distance to expressway IC & $\mathrm{km}$ & 0.90 & 8.00 & 3.11 & 1.28 \\
\hline Distance to major arterial roads & $\mathrm{km}$ & 0.20 & 2.50 & 1.25 & 0.79 \\
\hline Distance to subway station & $\mathrm{m}$ & 50.00 & 1500.00 & 552.41 & 530.58 \\
\hline Width of front road & $\mathrm{m}$ & 10.0 & 44.0 & 21.06 & 8.54 \\
\hline Distance to CBD & $\mathrm{km}$ & 6.1 & 33.4 & 15.17 & 9.60 \\
\hline Gross area & $\mathrm{m}^{2}$ & 24312.48 & 212733.49 & 108764.72 & 71749.37 \\
\hline Building age & year & 2.0 & 11.0 & 5.03 & 2.60 \\
\hline Ratio of amenity & $\%$ & 8.0 & 29.97 & 16.51 & 5.64 \\
\hline Center cored & dummy & 0.0 & 1.0 & 0.28 & 0.45 \\
\hline Parking lot per gross area & & 0.003 & 0.013 & 0.007 & 0.001 \\
\hline Sales price & USD & 104667 & 1375889 & 451516.35 & 190375.09 \\
\hline Unit size & $\mathrm{m}^{2}$ & 87.12 & 1239.64 & 250.77 & 113.26 \\
\hline Total floor of the building & story level & 11.0 & 40.0 & 23.08 & 9.69 \\
\hline Distance to elevator & $\mathrm{m}$ & 2.00 & 40.00 & 16.53 & 7.85 \\
\hline Two way balconies & dummy & 0.0 & 1.0 & 0.28 & 0.45 \\
\hline
\end{tabular}



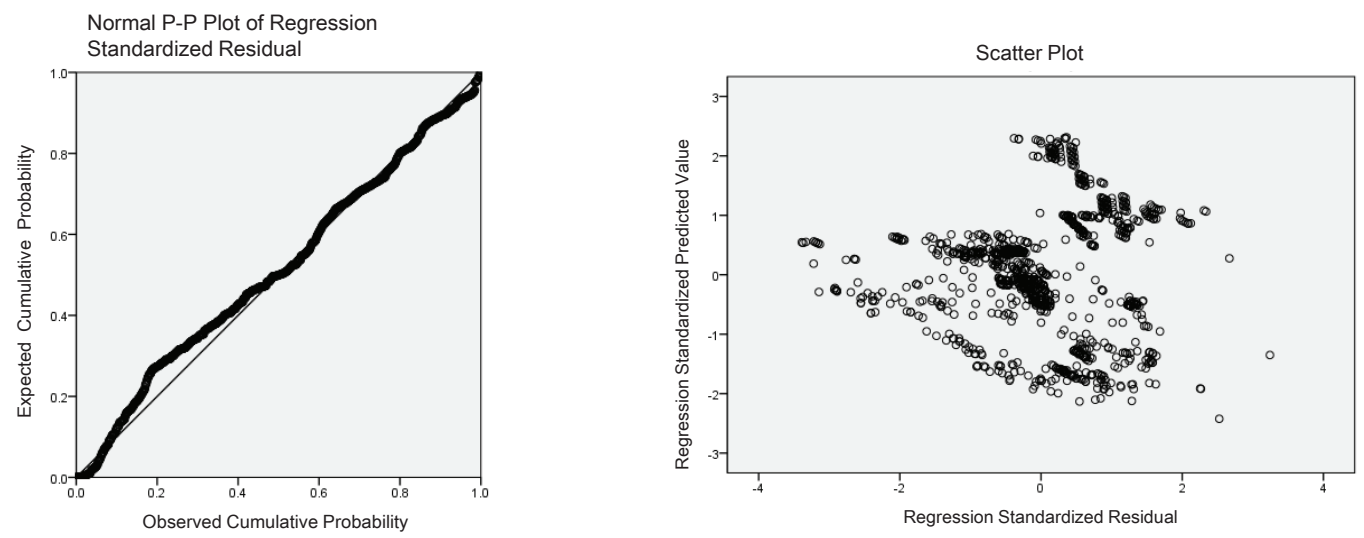

Figure 5. Residual test of model 1: normal probability plot (left) and scatter plot (right)
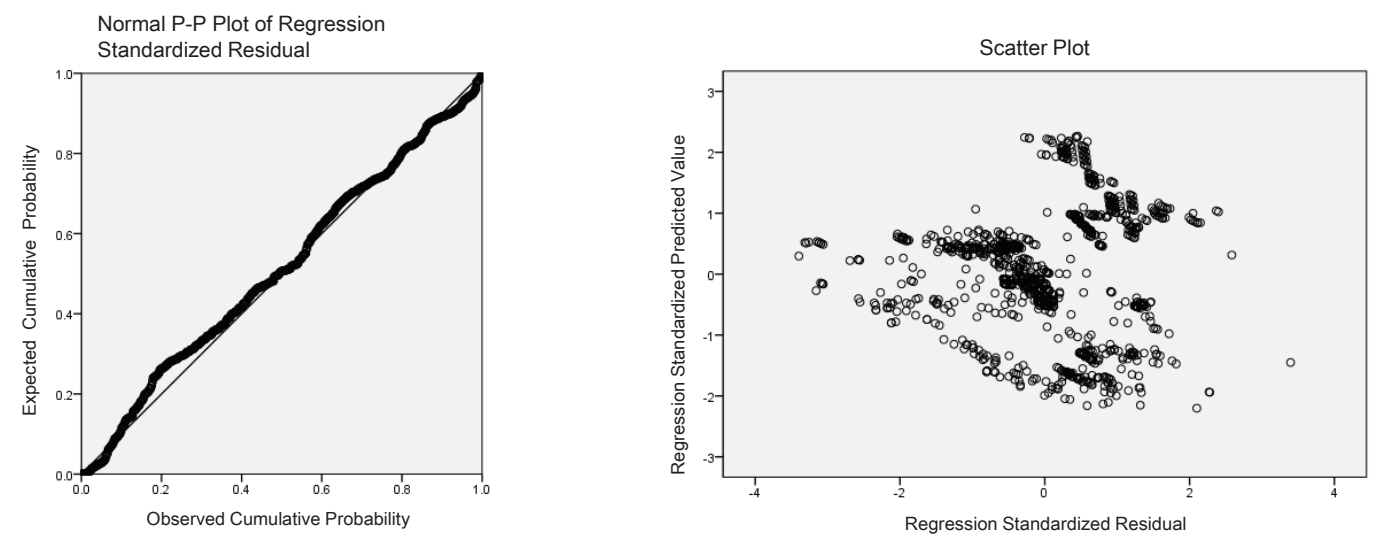

Figure 6. Residual test of model 2: normal probability plot (left) and scatter plot (right)

Table 7. Results of regression model

\begin{tabular}{|c|c|c|c|c|c|c|c|}
\hline & & \multicolumn{3}{|c|}{ Model 1} & \multicolumn{3}{|c|}{ Model 2} \\
\hline & Variables & B & $\mathrm{T}$ & VIF & B & $\mathrm{T}$ & VIF \\
\hline & (constant) & $\begin{array}{l}1803.075 \\
(170.076)\end{array}$ & 10.062 & & $\begin{array}{l}1654.078 \\
(181.013)\end{array}$ & 9.138 & \\
\hline \multirow[t]{7}{*}{ Location } & National industrial complex & $\begin{array}{c}-290.440^{* * *} \\
(46.502)\end{array}$ & -6.246 & 7.272 & $\begin{array}{c}-278.593^{* * *} \\
(45.968)\end{array}$ & -6.061 & 7.321 \\
\hline & Gyeong-gi province & $\begin{array}{c}-408.694^{* * *} \\
(48.636)\end{array}$ & -8.403 & 3.323 & $\begin{array}{c}-445.761^{* * *} \\
(102.969)\end{array}$ & -4.329 & 5.345 \\
\hline & Distance to expressway IC & $\begin{array}{c}-31.928^{* *} \\
(16.225)\end{array}$ & -1.968 & 6.916 & & & \\
\hline & Distance to major arterial roads & & & & $\begin{array}{c}-118.851^{* * *} \\
(20.140)\end{array}$ & -5.901 & 3.133 \\
\hline & Distance to subway station & $\begin{array}{c}-0.695^{* * *} \\
(0.051)\end{array}$ & -13.709 & 3.340 & $\begin{array}{c}-0.665^{* * *} \\
(0.044)\end{array}$ & -15.047 & 2.615 \\
\hline & Width of front road & $\begin{array}{c}10.351^{* * *} \\
(1.164)\end{array}$ & 8.892 & 1.890 & $\begin{array}{l}7.731^{* * *} \\
(1.203)\end{array}$ & 6.428 & 2.078 \\
\hline & Distance to CBD & $\begin{array}{c}-14.506^{* * * *} \\
(7.112)\end{array}$ & -2.040 & 4.548 & $\begin{array}{c}-15.229 * * * \\
(6.724)\end{array}$ & -2.265 & 6.263 \\
\hline
\end{tabular}


End of Table 7

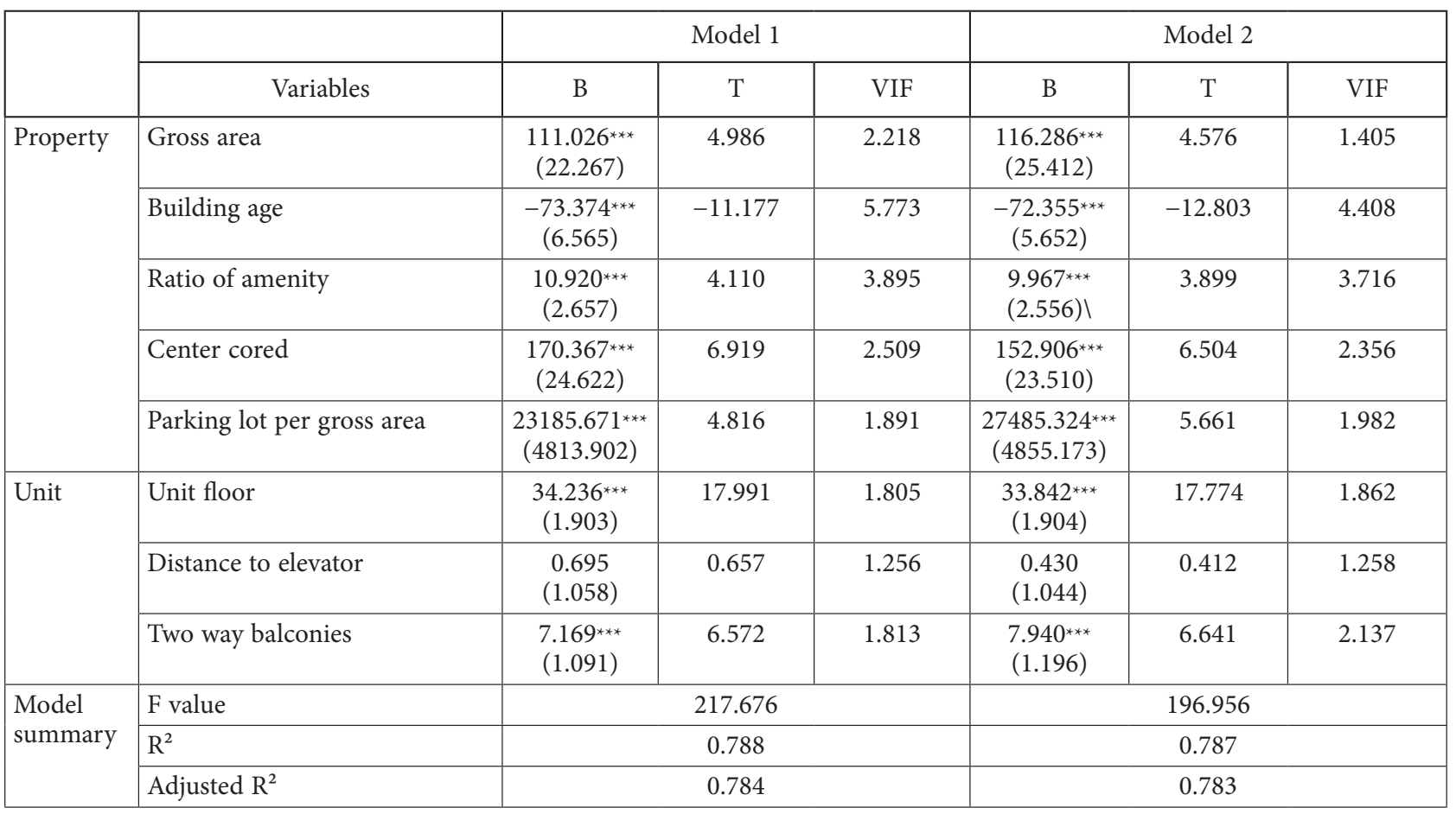

Notes: Parenthesis indicates standard errors. ${ }^{* *},{ }^{* *}$, denotes significance level of $1 \%, 5 \%$ respectively.

As for transportation variables, distance from $\mathrm{CBD}$, industrial transportation accessibility (i.e. distant from expressway interchange) and local transportation (i.e. distant from major arterial roads, distance from subway station) are all negatively related to sales price of a flatted factory. A flatted factory is of course one type of industrial property, and this paper seems to be the first empirical study which compares transportation convenience as a factor affecting the value of a flatted factory. Since flatted factories have gained popularity for office use purposes in Korea, public transportation variation is applied since office buildings are consequently influenced by public transportation accessibility.

Second, the gross area variable is significantly and positively related in with the price, so the hypothesis that large scale development is a positive factor affecting the value of a flatted factory is confirmed. As the size of flatted factory gets bigger, so does the ratio of amenity facilities.

As previous studies pointed out, regarding the age of a building, the older the building, the lower the price (Ambrose, 1990; Fehribach et al., 1993; Buttimer et al., 1997). The variables, the ratio of amenity facilities, the number of parking spaces, and the center-cored type structure, are all related in positive way as expected. It is confirmed that well-equipped amenities improve the satisfaction level of occupants, and positively affect the value of a flatted factory.

The floor level of each unit relates positively with its price. When the floor level is higher, a better view usually follows, and so does the value of a building. Corner units with two-way balconies have better views and ventilation and therefore their price range is mostly higher than the average. Corner units with two-way balconies are posi- tively related to its price, though the distance between the elevator and the unit is not.

\section{Discussion and conclusion}

\section{Summary of results and discussion}

The purpose of this paper is to analyze factors affecting flatted factory price. Flatted factories, nowadays, have drawn attention as investment goods from developers and investors. Compared to office buildings, the strengths and merits of these properties are that they are relatively low priced and less strictly regulated. The government offers acquisition and property tax benefits to support the supply of flatted factories. In addition, the risk of low vacancy rates in flatted factories is relatively low as compared to those of retail properties, which secures a stable rent. Factory residents are mostly corporate, not individuals, so that they prefer long-term contracts. With the fast growing popularity of flatted factory sales, investors and developers are drawing their attention to flatted factories not only for actual demand but for investment purposes. Compared to residential or retail property, the unit price of flatted factories is lower and has fewer strict loan regulations that apply. Therefore, a small scale investment approach is possible.

It is meaningful in that this is likely to be the first empirical study to examine the factors affecting sales prices in flatted factory buildings using real transacted data which enhance the model credibility. A Hedonic Price Model (HPM) is applied by using the sales data from 785 flatted factory units located in Seoul and Gyeong-gi Province in Korea. 
The results of this empirical study find that the sales price of flatted factories is affected by various characteristics: Location, Property, and Unit characteristics. As for location characteristics: locations in a national industrial complex or in Gyeong-gi Province are applied as control variables in order to reduce any present regional gap. The summarized results are as follows: First, location characteristics, represented by distance, mostly affect sales price negatively. Variables such as distance to express way interchange (negative), distance to major arterial roads (negative), distance to subway station (negative), width of front road (positive) and distance to CBD (negative) significantly affect the sales price of flatted factories.

Location characteristics are an important feature of factories' accessibility. This result confirms that flatted factory price is affected by both industrial transportation accessibility and local transportation convenience. Many earlier studies regarding industrial property value examined distance to expressway and distance to $\mathrm{CBD}$ as variables. However, the distance to subway station and to major arterial roads are used as variables for the first time in this study. This means public transportation should also be considered as a price affecting factor for industrial properties.

Second, this paper also finds that property characteristics, such as gross area (positive), building age (negative), ratio of amenity facilities (positive), center-cored structures (positive), number of parking per gross area (positive) are all significant factors affecting sales price of flatted factory units. As mentioned previously, to be considered as a grade ' $\mathrm{A}$ ' flatted factory building in the industry, a factories' gross area should be over $60,000 \mathrm{~m}^{2}$. It is because bigger size buildings attract a greater variety of enterprise which makes them more desirable. As for the gross area of flatted factory buildings, it is related to the size and amount of amenity facilities in buildings.

It is confirmed that well-equipped amenities can improve the satisfaction level of occupants. This may lead to the contract renewal of tenants, and, as a result, the vacancy rate of flatted factory buildings will decrease, securing steady rental profit. The result also shows that a center-cored structure positively affects price as compared to a dispersed-core structure. Therefore, when planning for developing flatted factories, the above findings should be considered as important factors affecting the value of a flatted factory.

Third, with respect to unit characteristics, unit floor level (positive) and corner unit with two-way balconies (positive) are significantly related to the sales price of flatted factories. Based on the results, it is verified that the price of flatted factories is affected by factors similar to those of apartments or office buildings: view and ventilation. This means that price decision factors of residential properties should be considered when deciding sales or rental price of flatted factories. In addition, it is strategically possible to price higher corner units with two-way balconies and units in higher floors (with views) than others. However, the distance to elevator is not a significant factor in flatted factories. Therefore, this result may possibly be used as a consideration for sale or rental price decision making.
Even though, at present, the study of flatted factories is at an early stage, this study can be differentiated from earlier studies, in that, it analyzes and classifies new variables as they relate to flatted factories. Above all, this paper includes distinctive characteristics for both office building and factory building use. It also presents both guidelines and implications not only to manufacturers with actual demand, but also to investors and developers for more informed decision making. Furthermore, it acts as a guide to practitioners and policy makers for the industrial property policy making process. Marketers may use the results as reference for the successful pricing strategy and sales marketing by focusing on customers' preferences. Additionally, suppliers of flatted factories can try to meet the needs of customers based on the specific unit characteristics, and eventually maximize their profit.

\section{Limitations}

Despite the interesting theoretical and practical implications discussed above, there are some limitations in this study as well. First, studies regarding flatted factories are still at an early stage. Therefore, it is not easy to find relevant existing literature. In addition, it is also hard to establish and collect relevant data. For those reasons, this paper refers to earlier studies on different kinds of industrial properties, such as industrial land, warehouses, or factories. Therefore, I hope that further related research can continue based on this paper as a stepping stone.

Second, flatted factories are mostly located in densely-populated areas, such as the Seoul metropolitan area. Therefore, the related data collected is also from the same area, which may show geographical limitations. Further study might deal with flatted factories in other cities nationwide, if possible, to find clear geographic distinctions and differences. More classification is necessary on specific unit characteristics as well.

Since geographically, flatted factories are not homogeneously distributed, rather they are concentrated in special areas, a price discrepancy might occur. Therefore, more studies should follow by using a spatial hedonic price method in the future. In this regard, it is necessary to upgrade and develop this study's results with the help of GIS techniques in near future.

Third, due to the limitations of data collection, it is hard to include various factors which possibly affect the price of flatted factories. Besides unit characteristics, such as number of drive-in doors or ceiling height (Ambrose, 1990), further studies including more varied factors, such as regional characteristics, should be followed.

The detailed study of amenities and owner occupation of flatted factories will be an interesting subject for further studies. They will definitely help customers and suppliers to thoroughly understand characteristics of flatted factories and related markets. The study of trends in property markets so far have mostly been focused on residential and commercial property, however, I hope this study could be used as a stepping stone to develop industrial property markets in the future. 


\section{References}

Ambrose, B. W. (1990). An analysis of the factors affecting light industrial property valuation. Journal of Real Estate Research, 5, 355-370.

Beekmans, J., Pascal, B., Erwin, K., \& Karel, M. (2014). A hedonic price analysis of the value of industrial sites. Journal of Property Research, 31, 108-130. https://doi.org/10.1080/09599916.2013.836556

Buttimer, R. J., Ronald, C. R., \& Ron, W. (1997). Industrial warehouse rent determinations in the Dallas/Fort Worth area. Journal of Real Estate Research, 13, 47-55.

Chang, I., \& Lee, H. (2009). Empirical study of industrial complex sale price discrimination. Applied Economics, 11, 207-224.

Coldwell, P. F., \& Dilmore, G. (1999). Who was first? An examination of an early hedonic study. Land Economics, 75, 620626. https://doi.org/10.2307/3147070

Cuadrado, J., Zubizarreta, M., Rojí, E., Larrauri, M., \& Álvarez, I. (2016). Sustainability assessment methodology for industrial buildings: three case studies. Civil Engineering and Environmental System, 33, 106-124.

https://doi.org/10.1080/10286608.2016.1148143

Derbes, M. J. (2002). Non-comparable industrial sales. Appraisal Journal, 70, 39-45.

DiPasquale, D., \& Wheaton, W. (1996). Urban economics and real estate markets. Englewood Cliffs, NJ: Prentice-Hall.

Dunse, N., Jones, C., Brown, J., \& Fraser, W. D. (2005). The spatial pattern of industrial rents and the role of distance. Journal of Property Investment and Finance, 23, 329-341. https://doi.org/10.1108/14635780510602408

Fehribach, F. A., Rutherford, R. C., \& Eakin, M. E. (1993). An analysis of the determinants of industrial property valuation. Journal of Real Estate Research, 8, 365-376.

Google Map Service. (n.d.). Retrieved from https://www.google. co.kr/maps/@36.5721377,127.1454272,8z?hl=en

Google Fusion Table. (n.d.). Retrieved from https://fusiontables. google.com/DataSource?dsrcid=implicit

Government Civil Petition Service. (n.d.). Retrieved from http:// www.minwon.go.kr

Hwang, E. S., \& Choi, M. S. (2014). A Study on the effect of the residential satisfaction degree by the move-in factors and the management service quality factors for knowledge industrial center. Journal of Residential Environment, 11, 157-171.

Industrial Cluster Development and Factory Establishment Act (ICDFEA), Article 2, 6th. Retrieved from http://www.law. go.kr/lsInfoP.do?lsiSeq=198503\&efYd=20171031\#0000

Jung, S. K., \& Choi, K. H. (2013). An analysis of the Seoul digital industrial complex's development process and an evaluation of its current stage as a cluster. Seoul Studies, 14, 245-265.

Keskin, B. (2008). Hedonic analysis of price in the Istanbul housing market. International Journal of Strategic Property Management, 12, 125-138. https://doi.org/10.3846/1648-715X.2008.12.125-138

Kim, I. J. (2009, November). A study on the policy alternatives of apartment-type factory systems. Seoul Studies, 10, 143-168.

Kim, Y. S. (2016). Industrial land supply and policy issues, KIET Research (pp. 45-53). Korea Institute for Industrial Economics \& Trade: Sejong, Korea.

Korea Appraisal Board, R-one System. (n.d.). Retrieved from http://www.r-one.co.kr/rone/

Korea Industrial Complex Corporation (KICOX). (2013). Miracle on the Han River, Nest on Half Century 1962 2012. Seoul, Korea.
Korea Industrial Complex Corporation. (n.d.). Retrieved from http://www.kicox.or.kr

Korea Land \& Housing Corporation (KLHC). (2011). Industrial site development guide. Seoul, Korea.

Korean Statistical Information Service. (n.d.). Retrieved from http:// kosis.kr/statHtml/statHtml.do?orgId=101\&tblId=DT_1J0A135

Kowalski, J. G., \& Paraskevopoulos, C. C. (1990). The impact of location on urban industrial land prices. Journal of Urban Economics, 27, 16-24. https://doi.org/10.1016/0094-1190(90)90021-E

Kryvobokov, M., \& Wilhelmsson, M. (2007). Analysing location attributes with a hedonic model for apartment prices in Donetsk, Ukraine. International Journal of Strategic Property Management, 11, 157-178.

https://doi.org/10.3846/1648715X.2007.9637567

Lancaster, K. (1966). A new approach to consumer theory. Journal of Political Economy, 74, 132-157. https://doi.org/10.1086/259131

Lee, J. W., \& Lee, C. M. (2006). Rent determinants of retail properties in Seoul. Journal of Korea Planning Association, 41, 75-90.

Lee, W. B. (2011, September 24-43). A study on the improvement plan for supplying activation of knowledge industry center. KIET.

Lee, W. B., \& Kim, S. K. (2014). An empirical research on the impact of growth in a national industrial complex on job creation. Journal of Korea Regional Development Association, 26, 79-100.

Lockwood, L. J., \& Rutherford, R. C. (1996). Determinants of industrial property value. Journal of Real Estate Economics, 24, 257-272. https://doi.org/10.1111/1540-6229.00690

Mesthrige, J. W., \& Poon, H. L. (2015). Assessing the impact of revitalized old industrial buildings on the value of surrounding properties: an empirical study. Facilities, 33(3), 245-261. https://doi.org/10.1108/F-11-2013-0084

Ministry of Land, Infrastructure, and Transport. (n.d.). Retrieved from http://english.molit.go.kr/intro.do

Oh, S. J. (2016). Price determining factors and market characteristics in industrial properties (Unpublished doctoral dissertation). Konkuk University, Seoul, Korea.

Park, B. K. (2010). Seeking for hope from industrial land. Seoul, Korea.

Park, J. C., \& Lee, K. M. (2015). A study on developing industry complex: focusing on hierarchical evaluation model. Institute of Industrial and Business Management, 38, 169-188.

Park, W. S. (2009). Location and policy factors influencing the move-in decision of apartment factory: case study of middle and small sized companies in Daegu City. Journal of Korean Association of Regional Geographers, 15, 409-420.

Rosen, S. (1974). Hedonic prices and implicit markets: product differentiation in pure competition. Journal of Political Economy, 82, 34-55. https://doi.org/10.1086/260169

ULI. (2001). Business park and industrial development handbook. ULI Development Handbook Series. Washington, D.C.: ULIthe Urban Land Institute.

Yui, C., \& Wong, S. (2005). The effects of expected transport improvements on housing prices. Urban Studies, 42, 113-125. https://doi.org/10.1080/0042098042000309720

Zhang, L., Li, Y., Stephenson, R., \& Ashuri, B. (2018). Valuation of energy efficient certificates in buildings. Energy and Buildings, 158, 1226-1240. https://doi.org/10.1016/j.enbuild.2017.11.014 